\title{
Upcycling of Vine Shoots: Production of Fillers for PHBV-Based Biocomposite Applications
}

\author{
Grégoire David $^{1} \cdot$ Laurent Heux $^{2} \cdot$ Stéphanie Pradeau ${ }^{2} \cdot$ Nathalie Gontard $^{1} \cdot$ Hélène Angellier-Coussy ${ }^{1}$
}

Accepted: 12 September 2020 / Published online: 19 September 2020

(c) The Author(s) 2020

\begin{abstract}
This paper aims at investigating the potential of vine shoots (ViSh) upcycling as fillers in novel poly(3-hydroxybutyrate3-hydroxyvalerate) (PHBV) based biocomposites. ViSh particles of around $50 \mu \mathrm{m}$ (apparent median diameter) were obtained combining dry grinding processes, and mixed with PHBV using melt extrusion. Thermal stability and elongation at break of biocomposites were reduced with increasing contents of ViSh particles (10, 20 and $30 \mathrm{wt} \%$ ), while Young's modulus and water vapor permeability were increased. It was shown that a surface gas-phase esterification allowed to significantly increase the hydrophobicity of ViSh particles (increase of water contact angles from $59^{\circ}$ to $114^{\circ}$ ), leading to a reduction of $27 \%$ in the water vapor permeability of the biocomposite filled with $30 \mathrm{wt} \%$ of ViSh. The overall mechanical performance was not impacted by gas-phase esterification, demonstrating that the interfacial adhesion between the virgin ViSh particles and the PHBV matrix was already good and that such filler surface treatment was not required in that case. It was concluded that ViSh particles can be interestingly used as low cost fillers in PHBV-based biocomposites to decrease the overall cost of materials.
\end{abstract}

Keywords Biocomposite $\cdot$ Poly(3-hydroxybutyrate-co-3-hydroxyvalerate) $\cdot$ Natural fibers $\cdot$ Surface properties $~$

Permeability

\section{Introduction}

Biocomposite materials have attained a growing trend, with a large potential for applications from automotive to packaging. The incorporation of lignocellulosic fillers into biosourced and biodegradable polymer matrices can offer economic and environmental benefits of a more 'circular'

Hélène Angellier-Coussy

helene.coussy@umontpellier.fr

Grégoire David

gregoire.david@supagro.fr

Laurent Heux

heux@cermav.cnrs.fr

Stéphanie Pradeau

stephanie.pradeau@cermav.cnrs.fr

Nathalie Gontard

nathalie.gontard@inrae.fr

1 JRU UMR 1208 IATE - Univ Montpellier, CIRAD, INRA, Montpellier SupAgro, 2 Place Pierre Viala, Bat 31, 34060 Montpellier Cedex 01, France

2 CNRS, CERMAV, Univ. Grenoble Alpes, 38000 Grenoble, France approach [1]. Two main categories of lignocellulosic biomass can be distinguished for the production of fillers, i.e. natural fibers grown or extracted for their high mechanical properties (e.g. hemp, flax, kenaf) and fillers derived from residues from agricultural, forestry or food industries. The first type of fibers is the most commonly used as reinforcing agents. The second category allows value addition to residues while producing sustainable composites. Their mechanical performances are usually lower than dedicated grown plants but they can perfectly suit for applications that do not have very demanding specifications.

In the viticulture sector, huge amounts of waste and byproducts are generated each year including, among organic solid residues, vine shoots, stalks and wine pomaces. Vine shoots (ViSh) correspond to the woody stems that are obtained after vine pruning that is essential to the vine cultivation. They are one of the most important primary agricultural residues being annually produced in large quantity (around 2 tons/ha/year) in wine regions [2]. Currently, these ViSh follow different fates depending on the region: they can either be collected and burnt, ground and left on the vineyards as soil amendment [2,3], or to a lesser extent collected and valorized for the extraction of polyphenols [4-6], 
the production of heating wood [7] or compost [8]. Given the biochemical and histological composition of ViSh, one other potential route could be their upcycling for biocomposites applications, as already investigated for other agricultural residues such as bagasse, wheat straw or corn stem [9-12]. However, very few papers deal with the use of ViSh as fillers in composites. ViSh were investigated as a raw materials to obtain a pulp potentially useable in composites [13]. In the study of Girones et al. [14], ViSh (filler content of $30 \mathrm{wt} \%$ ) were incorporated in LDPE and PP matrices. It was concluded that composites displayed lower mechanical properties than neat matrices or composites reinforced with long technical fibers such as flax. This reduction was attributed to the low aspect ratio (1.8) of the ViSh fragments obtained by grinding in a granulator equipped with a $2.5 \mathrm{~mm}$ sieve. In another paper, Kilinc et al. [15] studied HDPE-based composites filled with 5, 10 and $20 \mathrm{wt} \%$ of ViSh powder displaying a volume median apparent diameter $\left(\mathrm{d}_{50}\right)$ of $13.6 \mu \mathrm{m}$. Materials containing $10 \mathrm{wt} \%$ of ViSh exhibited the highest tensile strength and flexural strength. The addition of ViSh delayed the onset of thermal decomposition of HDPE.

It was shown that successive dry milling processes could be successfully used to obtain lignocellulosic fractions with controlled size [12]. As an example, cut milling of native wheat straw produced coarse fillers of around $0.5 \mathrm{~mm}\left(\mathrm{~d}_{50}\right)$, that could be further ground to give fine particles with $\mathrm{d}_{50}$ around $100-150 \mu \mathrm{m}$ particles and finally ground using ball milling to reach ultra-fine particles with a size of $20-10 \mu \mathrm{m}$ $[11,12]$. In case of PHBV-based composites, Berthet et al. [11] showed that decreasing wheat straw filler size resulted in improved material processability and higher filler contents due to a better filler dispersion within the polymer matrix and an improved filler/matrix adhesion. Indeed, it was shown that grinding resulted in an increased hydrophobicity of the particle surface [12]. Besides, the best mechanical properties were obtained with ultra-fine particles $\left(\mathrm{d}_{50}\right.$ of $\left.20 \mu \mathrm{m}\right)$. The thermal stability decreased with an increase in filler content.

Among polymer matrices, poly(3-hydroxybutyrate-3-hydroxyvalerate) (PHBV) has been reported to be bio-sourced and fully biodegradable [16-18]. This thermoplastic has physical properties close to conventional polymers. However, PHBV has some limitations, such as lower crystallization rate and higher production cost. High production cost of the PHBV-based materials can be minimized by incorporating the lignocellulose residues into the matrix [19].

The quality of the filler/matrix interface play an important role in the functional properties of composite materials [20]. Lignocellulosic materials (comprising cellulose, hemicelluloses or lignin) are hydrophilic in nature because of their high content of hydroxyl groups. Most of the matrices used are mostly hydrophobic, including PHBV, and interfacial adhesion between such polymeric matrices and hydrophilic natural fibers are very poor [20,
21]. Besides, the hydrophilic character of natural fibers makes them sensitive to moisture uptake which induces reduced mechanical properties. For these reasons, natural fillers are generally subjected to surface modifications in order to achieve maximum compatibility and therefore good adhesion in the composite [21]. There are many different physical and chemical strategies described in the literature to enhance the filler/matrix adhesion [21-24], even genetic modifications of flax fibers have been explored $[25,26]$. Esterification, which is a classical approach to produce biodegradable cellulose esters plastics [27, 28], is a potential way to obtain reinforcing materials for biocomposites [29-31]. Most of these esterification treatments are implemented with solvents in homogeneous [32,33] or heterogeneous phase [34-36]. In a previous study on PHBV-based composites, a gas-phase esterification with palmitoyl chloride gave recently promising results on cellulose fillers [37]. This solvent-free treatment improved surface hydrophobicity significantly, resulting in a better affinity between cellulose particles and the PHBV matrix. It substantially limited the negative effects observed for the incorporation of virgin cellulose into the composite. Furthermore, a low degree of substitution did not change the biodegradability of the esterified substrate [38]. Thiebaud and Borredon [39] explored esterification of sawdust without organic solvents using fatty acid chlorides to improve thermoplastic properties of wood. The reagent was in fact the solvent and the treatment was performed on low amount of wood. But to the best of our knowledge, such gas-phase esterification treatment has never been carried out on lignocellulosic particles targeting composite applications.

The objective of the present study was to assess the potential of a low-value agricultural residue from viticulture as reinforcing agents in fully biocomposite materials. In order to suit with the food packaging constraints, the ViSh were ground using the successive milling process until reaching an average size of $50 \mu \mathrm{m}$. This relative low size of fillers will increase the ductility which has been identified as bottleneck for PHBV-based composite (low strain at break). It was chosen to keep all the fractions obtained after dry grinding to valorize all the vine shoots without by-product and without solvent. In addition, the gas-phase esterification was applied for the first time on lignocellulosic particles to attempt to improve interfacial adhesion with the matrix. It would allow the comparison with grafted cellulose from the previous study [37]. For the first time, the structure-properties relationships in PHBV/ViSh composites were studied. The present paper focused on tensile properties and water vapor permeability. The functional performance of composites depending largely on interfacial filler/matrix interactions, a gas-phase esterification of ViSh particles was performed and its effect on filler and composite properties was studied. 


\section{Materials and Methods}

\section{Materials}

Vine shoots (ViSh) were kindly provided by INRA Pech Rouge (Gruissan, France). The vine species was Syrah, which is the most common in France. The average composition of dry vine-shoots was $38 \%$ of cellulose, $23 \%$ of hemicellulose, $24 \%$ of lignin, $3 \%$ of ashes and the rest includes a group of large molecules of different chemical families $[2,40]$. The shoots were first air dried outdoors during 2 months to get a moisture content of $20 \%$ (w.b) then dried 48 hours in oven at $60{ }^{\circ} \mathrm{C}$ to reach $5 \%$ (w.b.). Successive dry grinding steps were carried to get particles displaying an apparent median diameter of about $50 \mu \mathrm{m}$. A first coarse milling using a shredder (AXT 22D, Bosch, Germany) gave fragments of about $5 \mathrm{~cm}$ that were then ground with a knife mill (SM 300, Retch, Germany) using successively grids of 4 and $2 \mathrm{~mm}$. Thereafter, an impact mill (Fine Impact Mill UPZ, Germany) equipped with a $0.3 \mathrm{~mm}$ grid was used at $18,000 \mathrm{rpm}$. Finally, resulting particles were ground in a ball mill (Faure Equipments, France) during 10 hours in jars filled with $3 \mathrm{~kg}$ of steel balls ( $25 \%$ of the internal volume) displaying diameters of 1.2, 1.6 and $2.6 \mathrm{~cm}$ diameter (ratio 1:1:1). $150 \mathrm{~g}$ of biomass were milled by batch and the speed was set at $50 \mathrm{rpm}$ to avoid centrifugation. Once milled, ViSh particles were stored in a hermetic drum in presence of silica gel (around 0\% RH) at room temperature. ViSh particles were used as they were for the preparation of composites, with no sieving.

A commercial poly(3-hydroxybutyrate-3-hydroxyvalerate) (PHBV) containing around $3 \%$ of valerate was purchased from NaturePlast (PHI002 grade). As reported by the manufacturer, it had a true density of $1.24 \mathrm{~g} \mathrm{~cm}^{-3}$ and a melt flow index between 5 and $10\left(190{ }^{\circ} \mathrm{C} ; 2.16 \mathrm{~kg}\right)$. The polymer pellets were stored away from air and light as well as from source of heat.

\section{Gas-Phase Esterification of ViSh Particles}

Approximately $100 \mathrm{~g}$ of ViSh particles previously dried overnight at $60{ }^{\circ} \mathrm{C}$ were subjected to a gas-phase esterification treatment using palmitoyl chloride (Sigma-Aldrich), as described by David et al. [41]. The experimental set-up used in this study was developed at CERMAV laboratory (Grenoble) [42]. The reaction was conducted in a $2 \mathrm{~L}$ reactor at $100{ }^{\circ} \mathrm{C}$ and 2 mbar during $15 \mathrm{~h}$. ViSh particles were introduced in nylon mesh bags, which were positioned on a Teflon grid above the liquid reagent to avoid direct contact. The reagent was used in excess compared to surface hydroxyl groups $(20 \mathrm{~g})$. A constant nitrogen flow was used to evacuate the reaction by-products that were vacuumpumped. At the end of the reaction time, grafted ViSh were purified by Soxhlet extraction with acetone reflux for $6 \mathrm{~h}$. The final products were then oven dried at $60{ }^{\circ} \mathrm{C}$ overnight to remove any acetone leftover.

The same protocol was followed without reagent to obtain a control. Virgin, control and grafted ViSh particles were noted respectively ViSh-V, ViSh-C and ViSh-G.

\section{Preparation of Composite Materials}

Composite compounds were first produced with a lab-scale twin screw extruder, with a L/D ratio of 40 and a screw diameter of $16 \mathrm{~mm}$ (Eurolab, Thermo Scientific, Karlsruhe, Germany). It was equipped with a rod die of $3 \mathrm{~mm}$ of diameter and a pelletizer to produce granules. The screw speed was $300 \mathrm{rpm}$ and the flow rate was $1.0 \mathrm{~kg} \mathrm{~h}^{-1}$. The temperature profile from the feeding to the die varied from 80 to $180{ }^{\circ} \mathrm{C}$ (80-160-160-160-160-170-170-180-180-160 ${ }^{\circ} \mathrm{C}$ ). Virgin PHBV pellets and ViSh particles (either virgin or grafted) were previously dried at $60{ }^{\circ} \mathrm{C}$ before compounding. Four filler contents were used, i.e. 5, 10, 20 and $30 \mathrm{wt} \%$. Composite films displaying a thickness of $300 \mu \mathrm{m}$ were then prepared using a heated hydraulic press (20T, Pinette Emidecau Industries, Chalon-sur-Saône, France) from compounds previously produced by melt extrusion. Compounds were dried overnight at $60^{\circ} \mathrm{C}$ before processing. Compounds were first heated during $5 \mathrm{~min}$ at $178^{\circ} \mathrm{C}$ by putting the heating plates at the contact of granules and then compressed between two Teflon-coated plates (Taconic, France) for $4 \mathrm{~min}$ at $178{ }^{\circ} \mathrm{C}$ by increasing gradually the pressure from 20 bar to 150 bars. Films were then allowed to cool between the two Tefloncoated plates at room temperature for $5 \mathrm{~min}$ under a weight (around $1 \mathrm{~kg}$ ). All composite films were stored in a hermetic drum with silica gel (around 0\% RH) at room temperature.

\section{Solid-State ${ }^{13}$ C NMR}

Solid-state ${ }^{13} \mathrm{C}$ NMR experiments were performed with a Bruker Avance DSX $400 \mathrm{MHz}$ spectrometer operating at $100.6 \mathrm{MHz}$, using the combination of cross-polarization, high-power proton decoupling and magic angle spinning (CP/MAS). Standard conditions were 2000 scans with $2 \mathrm{~ms}$ of contact and $2 \mathrm{~s}$ of recycle delay. The acquisition time was $35 \mathrm{~ms}$ and the sweep width was $29,400 \mathrm{~Hz}$.

\section{Laser Granulometry}

Particle size distribution was determined from 0.01 to $10,000 \mu \mathrm{m}$ using a Mastersizer 2000 laser granulometer in wet mode (Malvern Instruments Ltd., United Kingdom). Particles were suspended in ethanol 95\% (v/v). Three values 
were identified to characterize the sample and allow comparison. The value of $d_{10}$ represents the particle size diameter for which $10 \%$ of particles (in volume or number) have a diameter less than that. Similarly, $\mathrm{d}_{50}$ represents de median and $\mathrm{d}_{90}$ the diameter from where the cumulative distribution of particles is $90 \%$. Measurements were done with at least 5 repetitions.

\section{Scanning Electron Microscope (SEM)}

The samples were examined with a Hitachi S4800 Scanning electron microscope (Technology platform of IEM Laboratory of the Balard Chemistry pole) with an acceleration voltage of $2 \mathrm{kV}$ after a coating with Pt by cathode pulverization using a SC7620 sputter coater (Quorum Technologies, Laughton, England). Observation were realized by the help of Didier Cot (IEM, Montpellier). In case of cryo-fractured section observations, the specimens were frozen in liquid nitrogen then fractured before coating.

The aspect ratio of particles after milling was determined with a AZ100 macroscope (Nikon, JP). Images were treated using the Image $\mathbf{J}$ software that viewed each particle as an ellipse and measured major and minor axes. Average aspect ratio values (ratio between the major axis and the minor axis) were calculated from both the number and the volume distributions.

\section{Surface Free Energy}

ViSh particles surface free energies were assessed by contact angle measurements, as already described by David et al. [41]. The dispersive $\left(\gamma^{\mathrm{d}}\right)$ and polar $\left(\gamma^{\mathrm{p}}\right)$ components were evaluated by applying the Owens-Wendt approach [43] by using five reference liquids, namely distillated water, ethylene glycol, diiodomethane, formamide and glycerol.

\section{Dynamic Vapor Sorption}

Water vapor sorption was measured at $20{ }^{\circ} \mathrm{C}$ using a controlled atmosphere micro-balance (DVS, Surface Measurement System Ltd., London, UK). A Cahn D-200 microbalance, with a precision of $0.1 \mu \mathrm{g}$, recorded the mass evolution of the materials according to the relative humidity. A pre-drying step was first run at $60{ }^{\circ} \mathrm{C}$ in an oven during $24 \mathrm{~h}$, then the sample was placed in the DVS equipment at $0 \% \mathrm{RH}$ for until reaching the equilibrium at $20{ }^{\circ} \mathrm{C}$. In the case of cellulose, $1 \mathrm{mg}$ of cellulose was deposited in an aluminum pan (DSC Tzero® pans provided by TA Instruments), which was placed in the DVS nacelle. Water vapor sorption isotherms were determined from the equilibrium moisture contents at each RH step. Tests were performed at least in duplicate.

\section{Differential Scanning Calorimetry (DSC)}

The thermal properties of composites were investigated using a thermo-modulated calorimeter (Q200 modulated DSC, TA Instruments, New Castle, USA). Approximately $10 \mathrm{mg}$ of sample were analyzed in hermetically sealed aluminium pans (Tzero Aluminium Hermetic pan, TA Instruments, New Castle, USA). Analyses were performed in triplicate. The purge gas was nitrogen, with a flow rate of $50 \mathrm{~mL} \mathrm{~min}{ }^{-1}$. Each sample was first heated up to $200{ }^{\circ} \mathrm{C}$ at $10{ }^{\circ} \mathrm{C} \mathrm{min}{ }^{-1}$, then cooled at $10{ }^{\circ} \mathrm{C} \mathrm{min}^{-1}$ until temperatures reached $-30{ }^{\circ} \mathrm{C}$, and finally heated again from -30 to $200{ }^{\circ} \mathrm{C}$ at a heating rate of $10{ }^{\circ} \mathrm{C} \mathrm{min}^{-1}$. From the resultant thermogram, crystallization temperature $\left(\mathrm{T}_{\mathrm{c}}\right)$, melting temperature $\left(\mathrm{T}_{\mathrm{m}}\right)$ and melting enthalpy $(\Delta \mathrm{Hm})$ were measured. The polymer crystallinity was calculated as follows (1):

$X_{c}=\frac{\Delta H}{\Delta H_{m}^{0}\left(1-\frac{\% w t \text { filler }}{100}\right)} \times 100$

where $\Delta \mathrm{H}^{0}{ }_{\mathrm{m}}$ was the enthalpy of melting $100 \%$ crystalline polymer, (146 J g ${ }^{-1}$ for PHBV [44]), and \%wt was the weight fraction of the filler in the composite.

\section{Thermogravimetric Analysis (TGA)}

TGA under nitrogen flow $\left(50 \mathrm{~mL} \mathrm{~min}^{-1}\right)$ was carried out using a Mettler TGA2 apparatus (Schwerzebbach, Switzerland) equipped with a XP5U balance. The samples were heated at $10{ }^{\circ} \mathrm{C} \mathrm{min}{ }^{-1}$ from 25 to $600{ }^{\circ} \mathrm{C}$. The results were analyzed using STARe software. The maximum degradation temperature $\left(\mathrm{T}_{\mathrm{deg}}\right)$ corresponded to the temperature at which the degradation rate was maximum. The onset and offset degradation temperatures ( $\mathrm{T}_{\text {onset }}$ and $\mathrm{T}_{\text {offset }}$, respectively) were measured respectively when the first derivative of the weight loss became higher than $0.1 \% \mathrm{C}^{-1}$ and lower than $0.1 \% \mathrm{C}^{-1}$. Analyses were done in triplicate.

\section{Tensile Tests}

Mechanical properties were evaluated through tensile tests conducted at $23^{\circ} \mathrm{C}$ by a tensile tester (Zwick BZ2.5/TN1S, Metz, France) on dog-bone shaped film specimens (width of $4 \mathrm{~mm}$ and gauge length of $45 \mathrm{~mm}$ ). The specimens had been cut in $300 \mu \mathrm{m}$ composite films previously produced by thermopressing. Composite specimens were kept in a conditioned room at $23{ }^{\circ} \mathrm{C}$ and $50 \%$ humidity for at least $24 \mathrm{~h}$ before testing. Young's modulus (E), nominal stress at break $(\sigma)$, nominal strain at break $(\varepsilon)$ and energy at break were determined from stress-strain curves obtained with a 
cross-head speed of $1 \mathrm{~mm} \mathrm{m^{-1 }}$. At least ten replicates were realized for each formulation $(5,10,20$, and $30 \mathrm{wt} \%)$.

\section{Water Vapor Permeability}

Water vapor permeability (WVP) was gravimetrically determined at $23{ }^{\circ} \mathrm{C}$ using a modified ASTM E96 procedure. Discs of films (five repetitions) were sealed in permeation cells filled with distilled water that were put into a desiccator containing silica gel. A relative humidity $(\mathrm{RH})$ gradient equal to $0-100 \%$ was obtained (assuming that $\mathrm{RH}$ on the silica gel is negligible). The permeation surface was $9.08 \mathrm{~cm}^{2}$. Periodic weightings determined the rate of water vapor movement through the films. WVP $\left(\mathrm{mol} \mathrm{s}^{-1} \mathrm{~Pa}^{-1} \mathrm{~m}^{-1}\right)$ was calculated from (2):

$W V P=\frac{S \times e}{3600 \times A \times \Delta P \times M_{\mathrm{H}_{2} \mathrm{O}}}$

where $\mathrm{S}$ was the slope of the weight change from the straight line $\left(\mathrm{g} \mathrm{h}^{-1}\right)$, A the permeation area $\left(\mathrm{m}^{2}\right)$, e the average specimen thickness $(\mathrm{m}), \Delta \mathrm{P}$ the saturation vapor pressure at $23{ }^{\circ} \mathrm{C}$ $(2809 \mathrm{~Pa})$, and $\mathrm{M}_{\mathrm{H} 2 \mathrm{O}}$ the molar mass of water $\left(\mathrm{g} \mathrm{mol}^{-1}\right)$.

\section{Results and Discussion}

\section{Impact of Gas-Phase Esterification on ViSh Particles Intrinsic Characteristics}

\section{Degree of Substitution}

The occurrence of the grafting and its extent was investigated by solid-state ${ }^{13} \mathrm{C}$ CP-MAS NMR.

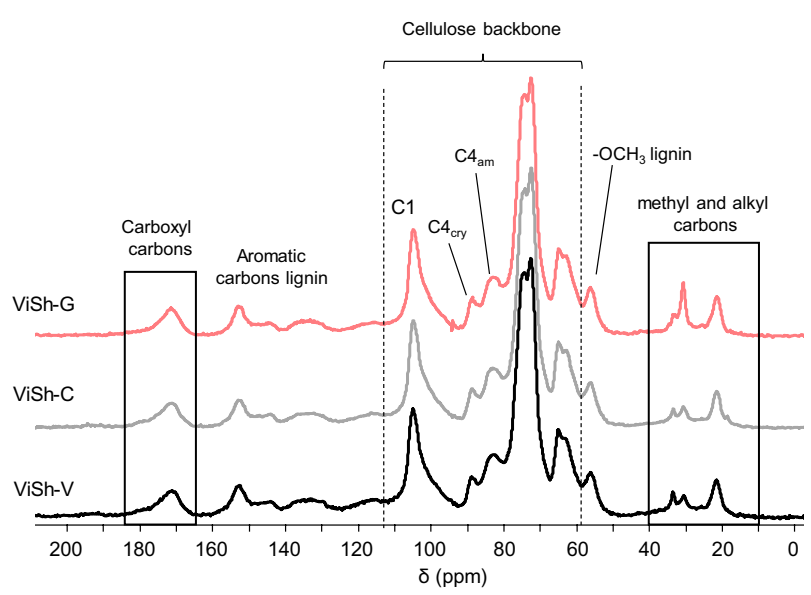

Fig. 1 Solid ${ }^{13} \mathrm{C}$ NMR spectra of ViSh-V (-), ViSh-C (-) and ViSh-G (-)
Figure 1 shows the spectra of the untreated, control and grafted ViSh particles. They all exhibit the characteristic signals of both cellulose and lignin. The assignation of the different carbon signals was achieved according to literature [45-47]. Concerning the virgin sample ViSh-V, the main peaks, between 60 and 115 ppm, corresponded to the polysaccharidic chains carbons that includes both cellulose and hemicelluloses, with the $\mathrm{C} 1$ peak at 105 ppm present in all polysaccharide and the $\mathrm{C} 4$ signal divided in two peaks, i.e. the first one at $83 \mathrm{ppm}$ corresponding to amorphous regions (cellulose and hemicelluloses) and the second one at $89 \mathrm{ppm}$ corresponding to crystalline regions of cellulose. These two latter peaks could be used to determine the crystallinity of the substrate according to the Newman method (3) [48]:

$X_{C}=\frac{I_{C 4 \text { cry }}}{I_{C 4 \text { cry }}+I_{C 4 \text { am }}}$

Using this method, all the samples had a crystallinity of $30 \%$, that includes the contribution of hemicelluloses [49]. This result confirmed that the reaction did not reduce the crystallinity staying at the surface of the particles.

The peak at $56 \mathrm{ppm}$ was assigned to methoxy carbons of lignin while the broad signals between 130 and 160 ppm were assigned to aromatic ring carbons of lignin. Besides, peaks between 10 and 40 ppm could be assigned to methyl, methylene and alkyl carbons of lignin [50] but also to possible lipophilic components (aldehydes, sterol ester and ester waxes) [51]. These lipophilic components could also explain the carboxyl signals between 170 and $182 \mathrm{ppm}$. It is thus worth noting that the spectrum of virgin ViSh particles already revealed the presence of carboxylic carbons (peak at $172 \mathrm{ppm}$ ) and of aliphatic carbons (peaks between 10 and $40 \mathrm{ppm}$ ). The spectra of virgin and control ViSh-V and ViSh-C samples were very similar with no distinct difference. On the contrary, ViSh-G was characterized by a slight increased intensity of the carbonyl signal at $173 \mathrm{ppm}$ but more visually with the higher intensity of the alkyl signal at $30 \mathrm{ppm}$ compared to virgin particles (Fig. 1). It evidenced the grafting of the fatty acid on the particles

The esterification was quantified calculating the degree of substitution (DS) that is usually applied for cellulosic substrate. The lignocellulose being more complex than pure cellulose, the esterification product could be also difficult to be identified. Hydroxyl groups from lignin and hemicellulose can also react during the esterification. Thus, the DS was calculated by assuming that only hydroxyl groups of cellulose were the reaction sites, as already assumed in case of wood esterification [46]. The DS was calculated from (4) et (5) using the integral of carbon $\mathrm{C} 1$ as reference to normalize the integral of the carboxyl signal $\left(\mathrm{I}_{\mathrm{C}=\mathrm{O}}\right)$ and integral of alkyl carbons $\left(\mathrm{I}_{\mathrm{C}-\mathrm{H}}\right)$ : 


$$
\begin{aligned}
& D S_{C-H}=\frac{I_{C-H(V i S h-G)}-I_{C-H(V i S h-C)}}{15} \\
& D S_{C=O}=\frac{I_{C=O(V i S h-G)}-I_{C=O(V i S h-C)}}{1}
\end{aligned}
$$

The DS of ViSh-G was calculated with respect to ViSh-C because during the Soxhlet extraction with acetone some extractives might be removed. The calculated values for $\mathrm{DS}_{\mathrm{C}-\mathrm{H}}$ and $\mathrm{DS}_{\mathrm{C}=\mathrm{O}}$ were respectively 0.007 and 0.011 . The DS were lower than for the grafting of cellulose particles in the same experimental conditions ( $\mathrm{DS}=0.02)$ [41]. It was most probably due to the presence of lignin that has a different reactivity and a reduced density of hydroxyl groups.

The ${ }^{13} \mathrm{C}$ NMR analysis proved the surface grafting with a fatty acid chloride of the ViSh particles without degrading their crystallinity.

\section{ViSh Particle Size and Morphology}

The particle size distribution was quantitatively assessed by laser granulometry, by assimilating particles to spheres of equivalent diameter (Table 1). It can be noted that the volume spans were high, reflecting the polydispersity of the ground ViSh sample. The $d_{50}$ in number was very low because no sieving or sorting was performed in order to recover all the biomass and not generate waste. The grafting had no significant impact on the apparent median diameter of particles.

Macroscopy and image analysis showed that ViSh particles were characterized by low aspect ratio values comparing to other natural fibers used in composites [12, 14, 52], ranging between 1.53 and 1.87 for number and volume averages respectively.

The morphology was qualitatively assessed by SEM observations (Fig. 2). At low magnification, all the samples displayed a similar appearance. Zooming on particles, ViSh-V (A2), ViSh-C (B2) and ViSh-G (C2) did not displayed difference at their surface. They all have a moderately rough surface with residual dusts aggregated on particles. It could be concluded from these analyses that the macroscopic structure of particles was not affected by the chemical treatment.

\section{Wettability of Grafted ViSh Particles}

The surface free energies of PHBV film and compressed tablets of ViSh particles were deduced from contact angle
Table 1 ViSh particles apparent diameters (in volume/ in number)

\begin{tabular}{lllll}
\hline Materials & $\mathrm{d} 10(\mu \mathrm{m})$ & $\mathrm{d} 50(\mu \mathrm{m})$ & $\mathrm{d} 90(\mu \mathrm{m})$ & Span* $^{*}$ \\
\hline ViSh-V & $7 \pm 1 / 0.5 \pm 0.1$ & $49 \pm 1 / 0.6 \pm 0.1$ & $191 \pm 10 / 1.2 \pm 0.1$ & $3.8 / 1.2$ \\
ViSh-C & $7 \pm 1 / 0.5 \pm 0.1$ & $48 \pm 1 / 0.6 \pm 0.1$ & $192 \pm 10 / 1.2 \pm 0.1$ & $3.8 / 1.2$ \\
ViSh-G & $6 \pm 1 / 0.5 \pm 0.1$ & $48 \pm 1 / 0.6 \pm 0.1$ & $197 \pm 14 / 1.3 \pm 0.1$ & $4.0 / 1.2$ \\
\hline
\end{tabular}

$*$ Span $=\left(\mathrm{d}_{90}-\mathrm{d}_{10}\right) / \mathrm{d}_{50}$
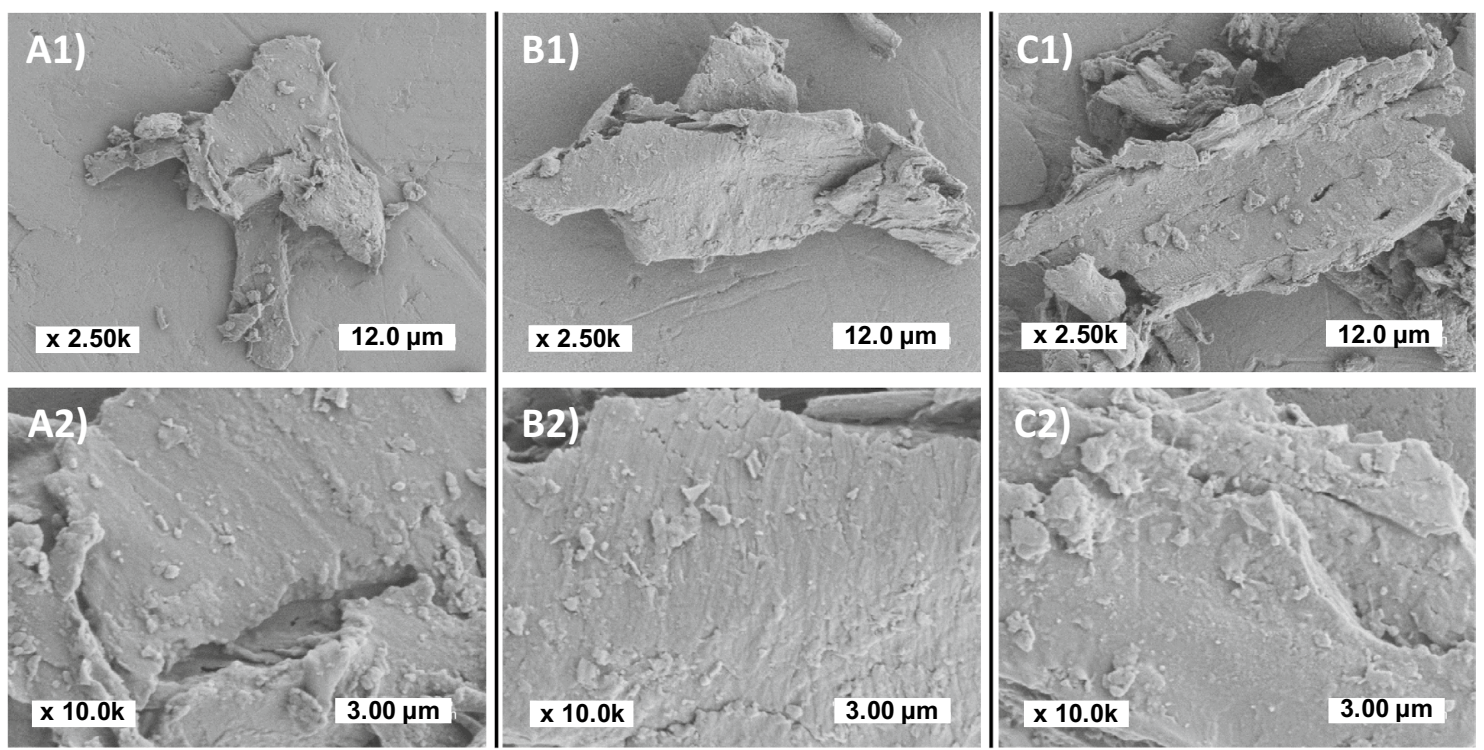

Fig. 2 SEM pictures of (A1-2) S-virgin and grafted cellulose (B1-2) S-control and (C1-2) S-grafted particles at different magnifications 
Table 2 Contact angle values $\left.{ }^{\circ}\right)$ with different reference liquids, polar $\left(\gamma^{\mathrm{p}}\right)$ and dispersive $\left(\gamma^{\mathrm{d}}\right)$ components of the surface free energy $(\gamma)$ of PHBV, ViSh-V, ViSh-C and ViSh-G

\begin{tabular}{|c|c|c|c|c|c|c|c|c|}
\hline \multirow[t]{2}{*}{ Sample } & \multicolumn{5}{|c|}{ Contact angle $\left({ }^{\circ}\right)$} & \multicolumn{3}{|c|}{$\begin{array}{l}\text { Surface free energy } \\
\left(\mathrm{mJ} \mathrm{m}^{-2}\right)\end{array}$} \\
\hline & Water & Ethylene glycol & Diiodom ethane & Formamide & Glycerol & $\gamma^{\mathrm{p}}$ & $\gamma^{\mathrm{d}}$ & $\gamma$ \\
\hline PHBV & $68 \pm 2$ & $45 \pm 2$ & $20 \pm 2$ & $39 \pm 1$ & $49 \pm 3$ & 6.2 & 42.6 & 48.8 \\
\hline ViSh-V & $59 \pm 4$ & $27 \pm 3$ & $24 \pm 3$ & $30 \pm 3$ & $46 \pm 4$ & 10.2 & 41.7 & 51.8 \\
\hline ViSh-C & $58 \pm 3$ & $29 \pm 2$ & $22 \pm 4$ & $27 \pm 2$ & $42 \pm 3$ & 10.7 & 42.2 & 52.9 \\
\hline ViSh-G & $114 \pm 3$ & $73 \pm 1$ & $25 \pm 4$ & $62 \pm 2$ & $93 \pm 3$ & 2.2 & 49.5 & 51.7 \\
\hline
\end{tabular}

measurements (Table 2). Virgin ViSh particles had a relative low polar component $\left(10.2 \mathrm{~mJ} \mathrm{~m}^{-2}\right)$. As expected, this value was lower than the polar component of cellulose particles due to the presence of lignin. However, common lignocellulosic fibers usually displayed polar component between 15 and $25 \mathrm{~mJ} \mathrm{~m}^{-2}$ and are considered as hydrophilic by nature [20]. Different reasons can explain this result. Lignocellulosic substrates are heterogeneous and it is often described that cellulose is mostly present in the bulk of particles or fibers. Thus non-cellulosic components can be present in a larger proportion at the surface and induce low polarity and low surface free energy. No data concerning the vine shoots surface free energy were found in the literature. In an overview of literature data for surface free energy of wood, it was reported that Douglas fir aspen or maple can display such value with polar component between 11.8 and $16.4 \mathrm{~mJ}$ $\mathrm{m}^{2}$ and dispersive component between 36.2 and $41.8 \mathrm{~mJ} \mathrm{~m}^{2}$ [53]. For example, Van Hazendonk et al. [54] found that flax fibers were very hydrophobic with polar component lower than $5 \mathrm{~mJ} \mathrm{~m}^{2}$. The surface free energy of $28.5-34.2 \mathrm{~mJ} \mathrm{~m}^{2}$ increased after fatty substances extraction to $40.3-43.1 \mathrm{~mJ}$ $\mathrm{m}^{2}$. An additional extraction of pectins and hemicelluloses further raised the fiber surface tension to reach the one of pure cellulose.

Gas-phase esterification induced a drastic decrease of the polar component of vine shoot particles, from 10.2 down to $2.2 \mathrm{~mJ} \mathrm{~m}^{-2}$, together with an increase of the dispersive component from 41.7 up to $49.5 \mathrm{~mJ} \mathrm{~m}^{-2}$. The increase in hydrophobicity was clearly highlighted by the increase in contact angles formed with polar solvents, including water (increase from $59^{\circ}$ for ViSh-V to $114^{\circ}$ for ViSh-G), ethylene glycol, formamide and glycerol. Results obtained for the ViSh-C demonstrated that such an increase in hydrophobicity was not ascribed to the experimental conditions notably the temperature treatment or the Soxhlet extraction. Interestingly, the ViSh-C sample that has been washed by Soxhlet displayed a slight increase of the polar component suggesting a partial removal of non-polar component. This result was consistent to the previously quoted work of Van Hazendonk et al. [54].

Finally, it is worth noting that PHBV was not that hydrophobic displaying a water contact angle of $68^{\circ}$, i.e. lower than $90^{\circ}$. The measure has been carried out after stabilization of the drop on the surface of the film. Berthet et al. [55] found PHBV with the same grade to be highly hydrophobic with almost null polar component and a water angle of $100^{\circ}$. In another study with the same PHBV grade, the water contact angle measured was $60^{\circ}$ [56]. Luo et al. [57] reported a water contact angle of $85.8^{\circ}$ although the surface energy was very closed to the present results. Therefore, PHBV was less hydrophobic than PP, which had a water contact angle of $97.2^{\circ}$ and a polar component of 2.0

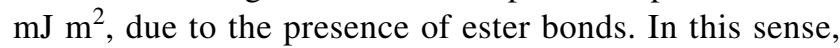
Ahankari et al. [9] showed that wheat straw fillers had better compatibility with PHBV matrix as compared to PP matrix.

\section{Water Vapor Sorption of ViSh Particles}

Dynamic vapor sorption (DVS) measurements were performed to investigate the impact of grafting on the water vapor sorption in ViSh particles (Fig. 3). The water uptake of virgin ViSh increased with the relative humidity displaying a sigmoidal curve already observed for cellulosic materials [58]. In the first part, lower than $60 \% \mathrm{RH}$, water was sorbed by hydrogen bonding then its concentration increased linearly in porous ViSh particles. In the second part, over $60 \% \mathrm{RH}$, the water sorption increased exponentially that can be explained by a clustering effect and the capillarity of water in the material [59]. Compared

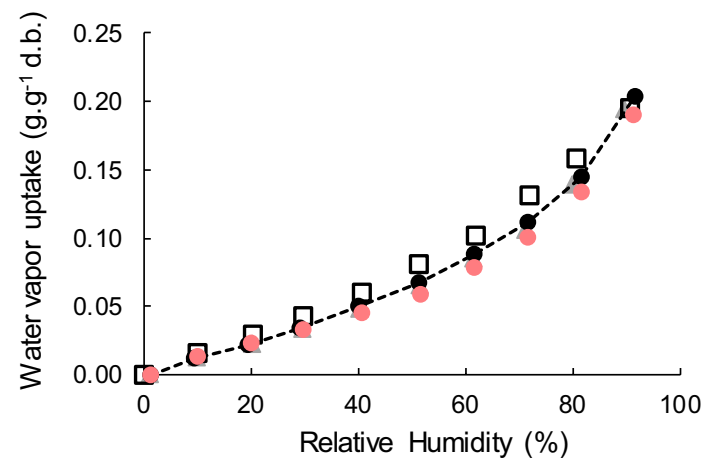

Fig. 3 Water vapor sorption isotherm of ViSh-V (๑), ViSh-C ( $)$, ViSh-G (๑) and cellulose $(\square)$ (data for cellulose are from [41], standard deviation bars are not visible as they are lower than the symbol size) 
to cellulose sample (from [41]), ViSh particles absorbed less water especially between 20 and $80 \%$ RH. This can be explained by the presence of lignin that it is known to have a lower water sensitivity.

ViSh-V and ViSh-C particles displayed identical isotherms that were very similar to the cellulosic substrate. The water uptake of ViSh-G was similar compared to particles without treatment, however from $50 \% \mathrm{RH}$ a slight decrease (10\%) was observed. This showed that the grafted hydrophobic moieties prevented the water vapor sorption. A slight decrease of crystallinity after grafting could explain the low difference in water vapor sorption since sorption occurs mainly in amorphous regions. Here, the grafting effect was less obvious than for water contact angle measurements because the water vapor reach more easily bulk remaining hydroxyl groups than liquid water. One has to remind that the very low grafting densities ( $\mathrm{DS}=0.01$ i.e. around $1 \%$ of the hydroxyl groups) is enough to modify the extreme surface [41] and hence change drastically the surface properties without changing the bulk properties.

These results showed an increase of moisture resistance of the ViSh after chemical treatment even if it was not drastic. According to previous results [41], moisture sorption was significantly affected by the degree of substitution of such as reaction. Thus, with higher DS, it could be expected to reach lower water sorption.

\section{Functional Properties of PHBV/ViSh Composites}

\section{Morphology of Composites: Qualitative Evaluation of the Filler/Matrix Interface}

The morphology of composites was qualitatively assessed by SEM observations of the cross-section of cryo-fractured PHBV-based materials (Fig. 4). Differences in interfacial filler/matrix adhesion were expected from the previous contact angle measurements ("Wettability of grafted ViSh particles" section). In the case of a filler content of $20 \mathrm{wt} \%$, fracture surfaces were rough and uneven. No difference of filler dispersion state was detected between the samples. Mechanical shearing forces induced during extrusion were probably enough to break potential particle aggregates. ViSh fillers, even not grafted, were found to be quite well embedded within the PHBV matrix and only small voids were noticed at the filler/matrix interface. From these SEM observations, it was difficult to conclude in a better filler/matrix adhesion in the case of ViSh-G. Indeed, composites displayed similar facies (Fig. 4a, b). The increased hydrophobicity of ViSh-G did not seem to improve the wettability of the filler by the PHBV matrix that was already good.

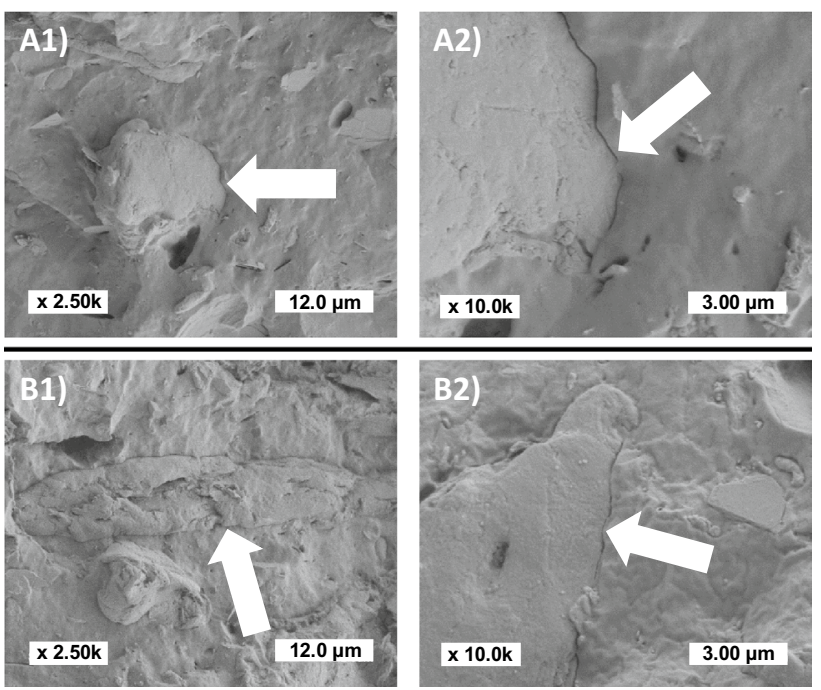

Fig. 4 SEM pictures of cryo-fractured sections: (A1-2) PHBV20ViSh-V, (B1-B2) PHBV-20ViSh-G. White arrows show the matrix/ filler interface

Table 3 Melting temperature $\left(\mathrm{T}_{\mathrm{m}}\right)$, crystallization temperature $\left(\mathrm{T}_{\mathrm{c}}\right)$ and crystallinity $\left(\mathrm{X}_{\mathrm{c}}\right)$ of PHBV-based composites

\begin{tabular}{lcclll}
\hline & $\mathrm{T}_{\mathrm{m}}{ }^{\mathrm{a}}\left({ }^{\circ} \mathrm{C}\right)$ & $\mathrm{T}_{\mathrm{m}}{ }^{\mathrm{b}}\left({ }^{\circ} \mathrm{C}\right)$ & $\mathrm{T}_{\mathrm{c}}\left({ }^{\circ} \mathrm{C}\right)$ & $\mathrm{X}_{\mathrm{c}}{ }^{\mathrm{a}}\left({ }^{\circ} \mathrm{C}\right)$ & $\mathrm{X}_{\mathrm{c}}{ }^{\mathrm{b}}\left({ }^{\circ} \mathrm{C}\right)$ \\
\hline PHBV & $174 \pm 1$ & $170 \pm 1$ & $123 \pm 1$ & $65 \pm 1$ & $69 \pm 1$ \\
PHBV-5ViSh-V & $173 \pm 1$ & $169 \pm 1$ & $120 \pm 1$ & $64 \pm 2$ & $68 \pm 1$ \\
PHBV-5ViSh-G & $173 \pm 1$ & $169 \pm 1$ & $119 \pm 1$ & $64 \pm 2$ & $67 \pm 1$ \\
PHBV-10ViSh-V & $172 \pm 1$ & $169 \pm 1$ & $118 \pm 1$ & $63 \pm 2$ & $67 \pm 1$ \\
PHBV-10ViSh-G & $172 \pm 1$ & $167 \pm 1$ & $117 \pm 1$ & $64 \pm 1$ & $65 \pm 1$ \\
PHBV-20ViSh-V & $170 \pm 1$ & $167 \pm 2$ & $115 \pm 2$ & $61 \pm 2$ & $63 \pm 3$ \\
PHBV-20ViSh-G & $171 \pm 1$ & $166 \pm 2$ & $114 \pm 2$ & $62 \pm 2$ & $63 \pm 2$ \\
PHBV-30ViSh-V & $169 \pm 1$ & $166 \pm 3$ & $113 \pm 3$ & $59 \pm 1$ & $63 \pm 2$ \\
PHBV-30ViSh-G & $170 \pm 1$ & $166 \pm 3$ & $113 \pm 3$ & $61 \pm 1$ & $64 \pm 2$ \\
\hline
\end{tabular}

${ }^{a}$ Measured at the first heating scan

${ }^{\mathrm{b}}$ Measured at the second heating scan

\section{Thermal Properties}

The degree of PHBV crystallinity in composite samples and their thermal properties were determined by DSC (Table 3 ). The PHBV matrix display a melting temperature of $174{ }^{\circ} \mathrm{C}$ and a crystallization temperature of $123{ }^{\circ} \mathrm{C}$. The relative high crystallinity of the matrix, $69 \%$, was due to the presence of boron nitride as nucleating agents added by the supplier. The crystallinity $\left(\mathrm{X}_{\mathrm{c}}\right)$ gradually decreased with the filler content from $65 \%$ to $59 \%$ for PHBV-30ViSh-V and to $61 \%$ for PHBV-30ViShG. The decrease in $\mathrm{X}_{\mathrm{c}}$ was thus slightly limited by the gas-phase esterification.

Melting $\left(\mathrm{T}_{\mathrm{m}}\right)$ and crystallization $\left(\mathrm{T}_{\mathrm{c}}\right)$ temperatures followed the same trend towards filler content for both ViSh particles grafted or not. No nucleation of PHBV was induced 
Fig. 5 TG (right) and DTG (left) curves of PHBV (-

), ViSh-V (-), S-control

$(-)$ and ViSh-G (

); PHBV-30ViSh-V (-

); PHBV-30ViSh-G (-

under $\mathrm{N} 2$
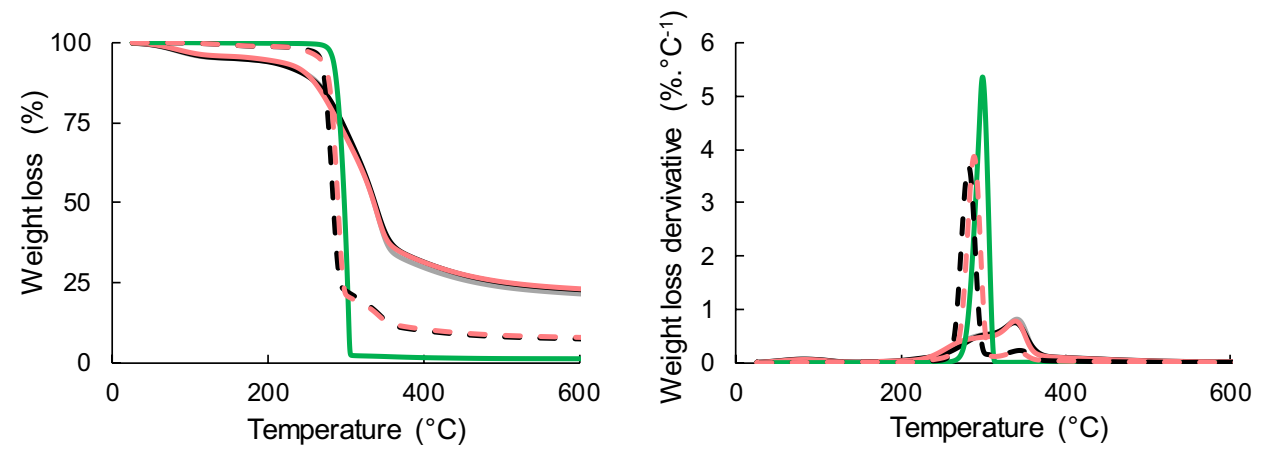

by the fillers. No significant change due to the grafting in the thermal properties of composites were observed.

Figure 5 shows the TGA and DTGA curves of the PHBV, ViSh fillers and PHBV/ViSh composites (filler content of $30 \mathrm{wt} \%$ ). The PHBV weight loss occurred in a one-step degradation process from 270 to $313^{\circ} \mathrm{C}$ as proven by the single peak in DTG. The degradation temperature of PHBV was $298{ }^{\circ} \mathrm{C}$ (Table 4).

Filler thermal stability is an important aspect to be considered regarding thermoplastic composites. If the studied filler has a low degradation temperature, it could be not suitable for producing composites with thermoplastics. In case of PHBV-based composite, the maximum processing temperature was $180^{\circ} \mathrm{C}$.

The TGA curves displayed an initial decrease below $120^{\circ} \mathrm{C}$ due to loss of moisture. Then, the decomposition of the ViSh filler started around $230{ }^{\circ} \mathrm{C}$ with the decomposition of pectin and non-structural hemicelluloses present in the ViSh. This suggests that these ViSh can be suitable for processing with polymers such as polyolefins having a melt temperature below $220^{\circ} \mathrm{C}$. The melt extrusion, used in the present study, did not thermally degraded ViSh fillers. The major decomposition temperature of ViSh at
$340{ }^{\circ} \mathrm{C}$ is due to the decomposition of cellulose. The ViSh residues at $600{ }^{\circ} \mathrm{C}$ under nitrogen represented around $23 \%$ indicating a high amount of lignin [60]. The thermal stability of ViSh was close to the one of wood flour [61]. Gas-phase esterification had no significant effect on the thermal stability of ViSh particles.

The thermal degradation of PHBV-ViSh composites occurred in a two-step degradation process. The first thermal degradation step corresponded to the PHBV matrix, then the second degradation step was ascribed to degradation of ViSh fillers. The composite degradation maxima occurred at temperature a little lower than that of PHBV. A shifting was observed from $298{ }^{\circ} \mathrm{C}$ for neat $\mathrm{PHBV}$ to $282{ }^{\circ} \mathrm{C}$ for PHBV-30ViSh-V composites and $289{ }^{\circ} \mathrm{C}$ for PHBV-30ViSh-G materials. The pro-degrading effect of ViSh was thus lower in the case of grafted ViSh. The residue at $600{ }^{\circ} \mathrm{C}$ of composites were principally due to the presence of boron nitride in PHBV and to mineral compounds in ViSh fillers. The residue increased proportionally with the filler content. ViSh-V and ViSh-G had a similar residual mass whereas composites with ViSh-G had a higher residual mass than composites with ViSh-V which was due to slightly higher filler contents.
Table 4 Results of thermogravimetric analysis

\begin{tabular}{lllllr}
\hline Materials & $\mathrm{T}_{\operatorname{deg}(1)}\left({ }^{\circ} \mathrm{C}\right)$ & $\mathrm{T}_{\operatorname{deg}(2)}\left({ }^{\circ} \mathrm{C}\right)$ & $\mathrm{T}_{\text {onset }}\left({ }^{\circ} \mathrm{C}\right)$ & $\mathrm{T}_{\text {offset }}\left({ }^{\circ} \mathrm{C}\right)$ & Residue $(\%)$ \\
\hline PHBV & $298 \pm 1$ & - & $270 \pm 1$ & $313 \pm 2$ & $1.3 \pm 0.1$ \\
ViSh-V & - & $338 \pm 1$ & $233 \pm 1$ & $387 \pm 1$ & $23.0 \pm 0.1$ \\
ViSh-C & - & $341 \pm 1$ & $234 \pm 1$ & $387 \pm 1$ & $21.7 \pm 0.2$ \\
ViSh-G & - & $338 \pm 1$ & $233 \pm 1$ & $390 \pm 1$ & $22.8 \pm 0.3$ \\
PHBV-5ViSh-V & $293 \pm 1$ & $340 \pm 2$ & $268 \pm 1$ & $307 \pm 2$ & $2.6 \pm 0.3$ \\
PHBV-5ViSh-G & $293 \pm 1$ & $341 \pm 1$ & $267 \pm 1$ & $307 \pm 1$ & $2.9 \pm 0.1$ \\
PHBV-10ViSh-V & $287 \pm 1$ & $346 \pm 3$ & $263 \pm 1$ & $302 \pm 1$ & $3.5 \pm 0.1$ \\
PHBV-10ViSh-G & $290 \pm 1$ & $342 \pm 2$ & $262 \pm 1$ & $304 \pm 1$ & $3.8 \pm 0.1$ \\
PHBV-20ViSh-V & $282 \pm 1$ & $345 \pm 1$ & $259 \pm 1$ & $300 \pm 1$ & $5.8 \pm 0.0$ \\
PHBV-20ViSh-G & $288 \pm 1$ & $342 \pm 1$ & $257 \pm 1$ & $302 \pm 1$ & $6.3 \pm 0.0$ \\
PHBV-30ViSh-V & $282 \pm 1$ & $344 \pm 1$ & $256 \pm 1$ & $361 \pm 1$ & $7.4 \pm 0.1$ \\
PHBV-30ViSh-G & $289 \pm 1$ & $341 \pm 1$ & $253 \pm 1$ & $356 \pm 1$ & $7.9 \pm 0.1$ \\
\hline
\end{tabular}


Fig. 6 Stress-strain curves of the different materials.

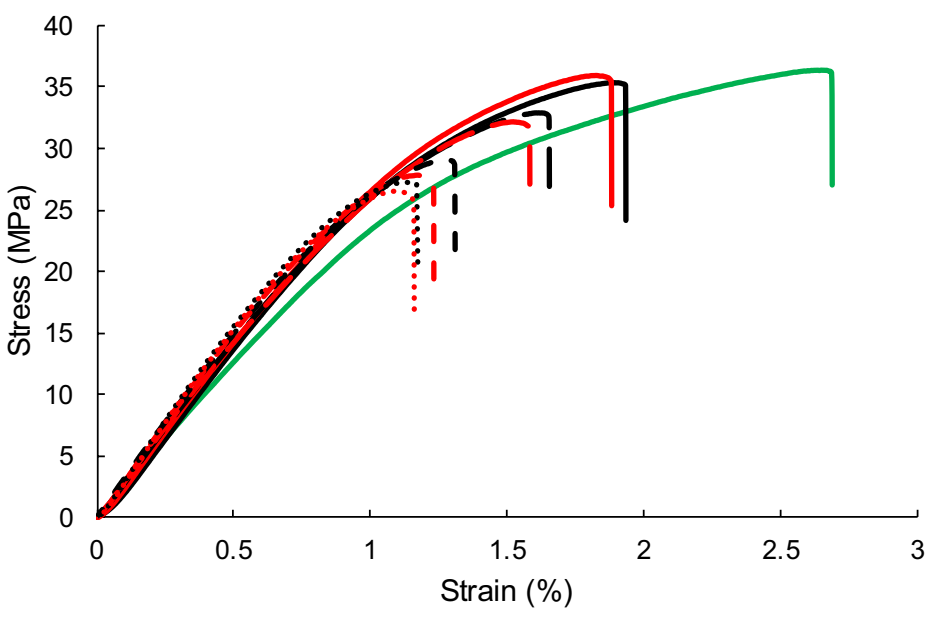

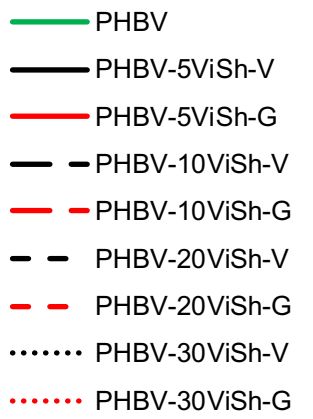

Table 5 Tensile properties (Young's modulus, nominal stress at break, nominal strain at break, and energy at break) of PHBV-based biocomposites

\begin{tabular}{lllll}
\hline Materials & $\begin{array}{l}\text { Young's modulus } \\
(\mathrm{GPa})\end{array}$ & Stress at break (MPa) & $\begin{array}{l}\text { Strain at break } \\
(\%)\end{array}$ & ${\text { Energy at break }\left(\mathrm{mJ} \mathrm{cm}^{-3}\right)}$ \\
\hline PHBV & $2.6 \pm 0.1(\mathrm{a})^{*}$ & $36.5 \pm 0.4(\mathrm{a})^{*}$ & $2.65 \pm 0.36(\mathrm{a})^{* *}$ & $649 \pm 110(\mathrm{a})^{* *}$ \\
PHBV-5ViSh-V & $3.0 \pm 0.1(\mathrm{c})^{*}$ & $35.1 \pm 1.4(\mathrm{~b})^{*}$ & $1.62 \pm 0.19(\mathrm{a}, \mathrm{b})^{* *}$ & $344 \pm 62(\mathrm{ab})^{* *}$ \\
PHBV-5ViSh-G & $3.0 \pm 0.1(\mathrm{c})^{*}$ & $35.4 \pm 1.3(\mathrm{~b})^{*}$ & $1.71 \pm 0.17(\mathrm{a}, \mathrm{b})^{* *}$ & $373 \pm 54(\mathrm{ab})^{* *}$ \\
PHBV-10ViSh-V & $2.9 \pm 0.1(\mathrm{~b})^{*}$ & $31.4 \pm 1.9(\mathrm{c})^{*}$ & $1.56 \pm 0.12(\mathrm{~b})^{* *}$ & $299 \pm 38(\mathrm{~b})^{* *}$ \\
PHBV-10ViSh-G & $2.9 \pm 0.1(\mathrm{~b})^{*}$ & $31.4 \pm 1.2(\mathrm{c})^{*}$ & $1.55 \pm 0.15(\mathrm{~b})^{* *}$ & $297 \pm 38(\mathrm{~b})^{* *}$ \\
PHBV-20ViSh-V & $3.1 \pm 0.1(\mathrm{c}, \mathrm{d})^{*}$ & $29.6 \pm 1.1(\mathrm{~d})^{*}$ & $1.25 \pm 0.06(\mathrm{c})^{* *}$ & $218 \pm 21(\mathrm{c})^{* *}$ \\
PHBV-20ViSh-G & $3.2 \pm 0.1(\mathrm{~d}, \mathrm{e})^{*}$ & $28.2 \pm 0.7(\mathrm{e})^{*}$ & $1.14 \pm 0.06(\mathrm{c})^{* *}$ & $186 \pm 15(\mathrm{c})^{* *}$ \\
PHBV-30ViSh-V & $3.3 \pm 0.2(\mathrm{e})^{*}$ & $27.3 \pm 1.0(\mathrm{e})^{*}$ & $1.14 \pm 0.07(\mathrm{c})^{* *}$ & $186 \pm 16(\mathrm{c})^{* *}$ \\
PHBV-30ViSh-G & $3.2 \pm 0.1(\mathrm{e})^{*}$ & $26.3 \pm 0.4(\mathrm{f})^{*}$ & $1.08 \pm 0.04(\mathrm{c})^{* *}$ & $186 \pm 9(\mathrm{c})^{* *}$ \\
\hline
\end{tabular}

*Groups from LSD Fischer's test $\mathrm{p}=0.05$

**Groups from Dunn's test $\mathrm{p}=0.05$

\subsubsection{Mechanical Properties}

Figure 6 shows typical tensile curves for pure PHBV and PHBV-based composites filled with virgin or grafted ViSh particles. The mechanical properties extracted from these plots are summarized in Table 5 with mean and standard deviations. First, it can be noted that composites had lower mechanical properties than PHBV matrix. As soon as ViSh particles were added the strain at break of the composite decreased, with a reduction of $38 \%$ in case of PHBV-5ViSh$\mathrm{V}$. The strain at break decreased with increasing filler content, reaching $1.14 \%$ for PHBV-30ViSh-V, which showed the brittle behavior of the composite. The gas phase esterification did not impact significantly this property. Similarly, the effect of the grafting on the stress at break was studied. In both cases, i.e. virgin or grafted ViSh, the stress at break decreased with increasing filler content. Comparably, the addition of cellulose particles were shown to reduce the ultimate properties of the biocomposites [37]. However, it was shown that esterification of pure cellulose particles allowed to limit this negative impact while no significant impact was noticed in the present study in the case lignocellulosic particles. It is worth noting that the decrease in the stress and strain at break was lower in the case of ViSh particles as compared to cellulose or wheat straw particles $[11,37]$. The addition of ViSh fillers resulted in an increase of Young's modulus values, most probably due to the higher tensile of ViSh fillers than the PHBV matrix [10]. However, it is worth noting that this increase was not higher than $30 \%$, likely due to the low aspect ratio of particles.

The Pukánszky's model was used to assess the quality of filler/matrix interfacial adhesion (6) [62]:

$\sigma_{c}=\sigma_{m} \lambda^{n}\left(\frac{1-x f}{1+2.5 x f}\right) e^{\left(B x_{f}\right)}$

where $\sigma_{\mathrm{c}}$ and $\sigma_{\mathrm{m}}$ are the stress at break of the composite and the matrix, respectively; $\mathrm{x}_{\mathrm{f}}$, the filler volume fraction. $\lambda$ is 


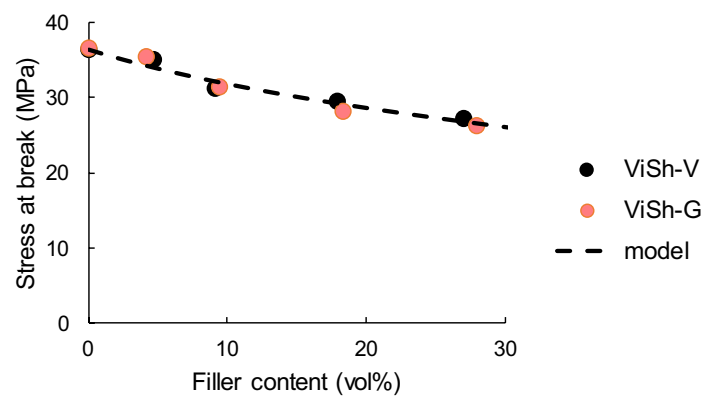

Fig. 7 Pukánszky's model applied for ViSh-V and ViSh-G based composites

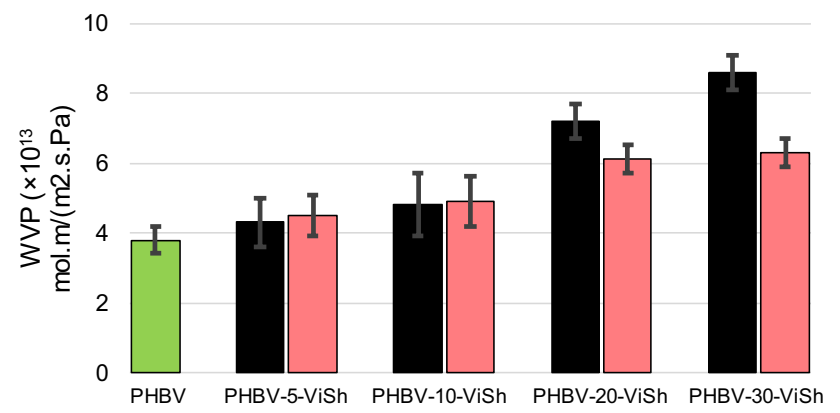

Fig. 8 Water vapor permeability (WVP) in PHBV-based biocomposites with ViSh-V (ロ) and ViSh-G ( $\square$ ) fillers

relative elongation and $\mathrm{n}$ accounts for to the strain hardening of the matrix. Because of the small elongation of the composite, $\lambda^{\mathrm{n}}$ can be neglected [63]. The model provides information about the filler/matrix interface thanks to the parameter B: a low B corresponds to a low adhesion. In the present study, in both cases (composites with ViSh-V and ViSh-G) experimental data were well fitted with $B=2$ (Fig. 7). It was higher than composites with virgin and grafted cellulose (B $=-0.8$ and 0.5 respectively) confirming the quite good adhesion [37]. This model also confirmed the idea that grafting did not have positive impact on the reinforcing properties of ViSh particles, due to the fact that PHBV and ViSh particles have quite similar surface free energy components. Therefore, no improvement of interfacial adhesion or adherence could be evidenced from tensile tests. Composites with $30 \mathrm{wt} \%$ of ViSh displayed acceptable tensile properties. An effort should be done concerning the strain at break

\section{Water Vapor Permeability (WVP)}

Water vapor permeability (WVP) of PHBV-based materials was assessed for increasing ViSh filler content (Fig. 8). The WVP value for PHBV film, $3.8 \times 10^{13} \mathrm{~mol} \mathrm{~m} /\left(\mathrm{m}^{2} \mathrm{~s} \mathrm{~Pa}\right)$, was in accordance with previous results [37]. The WVP of the present composites increased with the filler content. It was noticed that the crystallinity degree of the matrix decreased by the presence of the filler, thus the matrix was more permeable to water molecules. This increase was limited by the surface grafting of ViSh particles for high filler contents (20 and $30 \mathrm{wt} \%$ ). As an example, the WVP value of the film containing $30 \mathrm{wt} \%$ of filler was $27 \%$ lower with ViSh-G than with ViSh-V. It can be ascribed to the more hydrophobic character of grafted particles. Grafted filler hydrophobic nature was evidenced by water contact angle and surface free energy. Voids at the interface were promoted by weak interfacial adhesion and agglomeration of fillers, facilitating the permeability for water. The grafting probably improved a little the wettability of the ViSh particles. Similar results were observed in the case of gas-phase esterified cellulose [37] or torrefied wheat straw [55] in PHBV films.

\section{Conclusion}

Vine shoots (ViSh) particles of around $50 \mu \mathrm{m}$ (apparent median diameter) were incorporated in a PHBV matrix by melt extrusion. It was shown that such an addition resulted in a degradation of ultimate tensile properties of PHBV. The thermal stability was also negatively impacted by an increasing filler content. However, these negative effects were perfectly acceptable regarding some applications. Thus, green composites can surely provide a sustainable alternative to fossil sourced materials and a new way to manage agro-residues. Furthermore, at the economical point of view, the use of ViSh would decrease significantly the final cost of PHBV-based composites.

Besides, the surface compatibilization of ViSh particles with fatty chains via ester formation was achieved without solvent. ${ }^{13} \mathrm{C}-\mathrm{NMR}$ of the grafted particles revealed that the chemical modification was limited to the fiber surface. The backbone of lignocellulose was not altered with a constant crystallinity index. After grafting, the contact angle values jumped from $59^{\circ}$ to more than $114^{\circ}$, which confirmed the hydrophobization of ViSh particles. Mechanical properties of PHBV composites filled with 10, 20 and $30 \mathrm{wt} \%$ of particles revealed that the chemical grafting did not improved their reinforcing effect on the matrix. The lack of effect could be explained by the fact that PHBV is not such hydrophobic compared to polyolefins and the ViSh is already less hydrophilic compared to virgin cellulose. The water vapor permeability of composite films with $30 \mathrm{wt} \%$ of ViSh was reduced by $27 \%$ with grafted fillers. The gas-phase esterification showed higher effect in cellulose-based composites [37] than in lignocellulose-based composites.

Acknowledgements The authors would like to acknowledge Didier Cot (IEM, Montpellier) for his help concerning SEM observations. This work was carried out in the framework of the NoAW project, which is supported by the European Commission through the Horizon 
2020 research and innovation program under the Grant Agreement No. 688338.

\section{Compliance with Ethical Standards}

Conflict of interest The authors declare that they have no competing interest.

Open Access This article is licensed under a Creative Commons Attribution 4.0 International License, which permits use, sharing, adaptation, distribution and reproduction in any medium or format, as long as you give appropriate credit to the original author(s) and the source, provide a link to the Creative Commons licence, and indicate if changes were made. The images or other third party material in this article are included in the article's Creative Commons licence, unless indicated otherwise in a credit line to the material. If material is not included in the article's Creative Commons licence and your intended use is not permitted by statutory regulation or exceeds the permitted use, you will need to obtain permission directly from the copyright holder. To view a copy of this licence, visit http://creativecommons.org/licenses/by/4.0/.

\section{References}

1. Mohanty AK, Misra M, Hinrichsen G (2000) Biofibres, biodegradable polymers and biocomposites: an overview. Macromol Mater Eng 276-277:1-24

2. Galanakis CM (2017) Handbook of grape processing by-products. Elsevier, Amsterdam

3. FranceAgriMer (2016) Les enjeux de la valorisation de la biomasse non sylvicole en matériaux biosourcés

4. Sánchez-Gómez R, Zalacain A, Alonso GL, Salinas MR (2014) Vine-shoot waste aqueous extracts for re-use in agriculture obtained by different extraction techniques: phenolic, volatile, and mineral compounds. J Agric Food Chem 62:10861-10872. https://doi.org/10.1021/jf503929v

5. Delgado-Torre MP, Ferreiro-Vera C, Priego-Capote F et al (2012) Comparison of accelerated methods for the extraction of phenolic compounds from different vine-shoot cultivars. J Agric Food Chem 60:3051-3060. https://doi.org/10.1021/jf205078k

6. Karacabey E, Mazza G, Bayindirli L, Artik N (2012) Extraction of bioactive compounds from milled grape canes (Vitis vinifera) using a pressurized low-polarity water extractor. Food Bioprocess Technol 5:359-371. https://doi.org/10.1007/s11947-009-0286-8

7. Mendívil MA, Muñoz P, Morales MP et al (2013) Chemical characterization of pruned vine shoots from La Rioja (Spain) for obtaining solid bio-fuels. J Renew Sustain Energy 5:033113. https ://doi.org/10.1063/1.4808043

8. IFN, Solagro FCBA (2009) Biomasse forestière, populicole et bocagère disponible pour l'énergie à l'horizon 2020

9. Ahankari SS, Mohanty AK, Misra M (2011) Mechanical behaviour of agro-residue reinforced poly(3-hydroxybutyrate-co3-hydroxyvalerate), (PHBV) green composites: a comparison with traditional polypropylene composites. Compos Sci Technol 71:653-657. https://doi.org/10.1016/j.compscitech.2011.01.007

10. Panthapulakkal S, Sain M (2006) Injection molded wheat straw and corn stem filled polypropylene composites. J Polym Environ 14:265-272. https://doi.org/10.1007/s10924-006-0021-8

11. Berthet MA, Angellier-Coussy H, Chea V et al (2015) Sustainable food packaging: valorising wheat straw fibres for tuning PHBV-based composites properties. Composites Part A\&nbsp; 72:139-147. https://doi.org/10.1016/j.compositesa.2015.02.006
12. Montano-Leyva B, Silva GG, Gastaldi E et al (2013) Biocomposites from wheat proteins and fibers: structure/mechanical properties relationships. Ind Crops Prod 43:545-555. https://doi. org/10.1016/j.indcrop.2012.07.065

13. Mansouri S, Khiari R, Bendouissa N et al (2012) Chemical composition and pulp characterization of Tunisian vine stems. Ind Crop Prod 36:22-27. https://doi.org/10.1016/j.inder op.2011.07.036

14. Girones J, Vo LTT, Di Giuseppe E, Navard P (2017) Natural fillerreinforced composites: comparison of reinforcing potential among technical fibers, stem fragments and industrial by-products. Cellulose Chem Technol 51:839-855

15. Kilinc AC, Atagur M, Ozdemir O et al (2016) Manufacturing and characterization of vine stem reinforced high density polyethylene composites. Composites Part B\&nbsp; 91:267-274. https://doi. org/10.1016/j.compositesb.2016.01.033

16. David G, Michel J, Gastaldi E et al (2020) How vine shoots as fillers impact the biodegradation of PHBV-based composites. Int J Mol Sci 21:228. https://doi.org/10.3390/ijms21010228

17. Salomez M, George M, Fabre P et al (2019) A comparative study of degradation mechanisms of PHBV and PBSA under laboratoryscale composting conditions. Polym Degrad Stab 167:102-113. https://doi.org/10.1016/j.polymdegradstab.2019.06.025

18. Weng YX, Wang Y, Wang XL, Wang YZ (2010) Biodegradation behavior of PHBV films in a pilot-scale composting condition. Polym Test 29:579-587. https://doi.org/10.1016/j.polymertes ting.2010.04.002

19. Zhang L, Zhong J, Ren X (2017) Natural fiber-based biocomposites. In: Jawaid M, Sapuan S, Alothman O (eds) Green biocomposites. Green energy and technology. Springer, Cham, pp 31-70

20. Le Moigne N, Otazaghine B, Corn S et al (2018) Surfaces and interfaces in natural fibre reinforced composites-fundamentals, modifications and characterization. Springer, Cham

21. Belgacem MN, Gandini A (2005) The surface modification of cellulose fibres for use as reinforcing elements in composite materials. Compos Interfaces 12:41-75. https://doi.org/10.1163/15685 54053542188

22. George J, Sreekala MS, Thomas S (2001) A review on interface modification and characterization of natural fiber reinforced plastic composites. Polym Eng Sci 41:1471-1485. https://doi. org/10.1002/pen.10846

23. Li X, Tabil LG, Panigrahi S (2007) Chemical treatments of natural fiber for use in natural fiber-reinforced composites: a review. J Polym Environ 15:25-33. https://doi.org/10.1007/s1092 4-006-0042-3

24. Hubbe MA, Rojas OJ, Lucia LA (2015) Green modification of surface characteristics of cellulosic materials at the molecular or nano scale: a review. BioResources 10:6095-6206

25. Wróbel-Kwiatkowska M, Skórkowska-Telichowska K, Dymińska L et al (2009) Biochemical, mechanical, and spectroscopic analyses of genetically engineered flax fibers producing bioplastic (poly- $\beta$-hydroxybutyrate). Biotechnol Prog 25:1489-1498. https ://doi.org/10.1002/btpr.194

26. Szopa J, Wróbel-Kwiatkowska M, Kulma A et al (2009) Chemical composition and molecular structure of fibers from transgenic flax producing polyhydroxybutyrate, and mechanical properties and platelet aggregation of composite materials containing these fibers. Compos Sci Technol 69:2438-2446. https://doi.org/10.1016/j. compscitech.2009.06.017

27. Edgar KJ, Buchanan CM, Debenham JS et al (2001) Advances in cellulose ester performance and application. Prog Polym Sci 26:1605-1688

28. Wang P, Tao BY (1994) Synthesis and characterization of longchain fatty acid cellulose ester (FACE). J Appl Polym Sci 52:755761. https://doi.org/10.1002/app.1994.070520605 
29. Jandura P, Kokta BV, Riedl B (2001) Cellulose fibers/polyethylene hybrid composites: effect of long chain organic acid cellulose esters and organic peroxide on rheology and tensile properties. J Reinf Plast Compos 20:697-717. https://doi.org/10.1106/ Y1CM-4XV7-UAKV-VCH3

30. Pasquini D, Teixeira E, deda Curvelo M et al (2008) Surface esterification of cellulose fibres: processing and characterisation of low-density polyethylene/cellulose fibres composites. Compos Sci Technol 68:193-201. https://doi.org/10.1016/j.compscitec h.2007.05.009

31. Freire CSR, Silvestre AJD, Neto CP et al (2008) Composites based on acylated cellulose fibers and low-density polyethylene: effect of the fiber content, degree of substitution and fatty acid chain length on final properties. Compos Sci Technol 68:3358-3364. https:// doi.org/10.1016/j.compscitech.2008.09.008

32. McCormick CL, Lichatowich DK, Pelezo JA, Anderson KW (1979) Homogeneous solution reactions of cellulose, chitin, and other polysaccharides. J Polym Sci Part C\&nbsp; 17:479-484. https://doi.org/10.1021/bk-1980-0121.ch024

33. Vaca-Garcia C, Thiebaud S, Borredon ME, Gozzelino G (1998) Cellulose esterification with fatty acids and acetic anhydride in lithium chloride/N,N-dimethylacetamide medium. J Am Oil Chem Soc 75:315-319. https://doi.org/10.1007/s11746-998-0047-2

34. Jandura P, Riedl B, Kokta BV (2000) Thermal degradation behavior of cellulose fibers partially esterified with some long chain organic acids. Polym Degrad Stab 70:387-394. https://doi. org/10.1016/S0141-3910(00)00132-4

35. Uschanov P, Johansson L-S, Maunu SL, Laine J (2011) Heterogeneous modification of various celluloses with fatty acids. Cellulose 18:393-404. https://doi.org/10.1007/s10570-010-9478-7

36. Freire CSR, Silvestre AJD, Neto CP et al (2006) Controlled heterogeneous modification of cellulose fibers with fatty acids: effect of reaction conditions on the extent of esterification and fiber properties. J Appl Polym Sci 100:1093-1102. https://doi.org/10.1002/ app. 23454

37. David G, Gontard N, Angellier-Coussy H (2019) Mitigating the impact of cellulose particles on the performance of biopolyesterbased composites by gas-phase esterification. Polymers\&nbsp; 11:200. https://doi.org/10.3390/polym11020200

38. Glasser WG, Mccartney BK, Samaranayake G (1994) Cellulose derivatives with low degree of substitution. 3 . The biodegradability of cellulose esters using a simple enzyme assay. Biotechnol Prog 10:214-219. https://doi.org/10.1021/bp00026a011

39. Thiebaud S, Borredon ME (1995) Solvent-free wood esterification with fatty acid chlorides. Bioresour Technol 52:169-173. https:// doi.org/10.1016/0960-8524(95)00018-A

40. Dávila I, Gordobil O, Labidi J, Gullón P (2016) Assessment of suitability of vine shoots for hemicellulosic oligosaccharides production through aqueous processing. Bioresour Technol 211:636644. https://doi.org/10.1016/j.biortech.2016.03.153

41. David G, Gontard N, Guerin D et al (2019) Exploring the potential of gas-phase esterification to hydrophobize the surface of micrometric cellulose particles. Eur Polym J 115:138-146. https://doi. org/10.1016/j.eurpolymj.2019.03.002

42. Fumagalli M, Ouhab D, Boisseau SM, Heux L (2013) Versatile gas-phase reactions for surface to bulk esterification of cellulose microfibrils aerogels. Biomacromolecules 14:3246-3255. https:// doi.org/10.1021/bm400864z

43. Owens D, Wendt R (1969) Estimation of the surface free energy of polymers. J Appl Polym Sci 13:899-928. https://doi.org/10.1002/ app.1969.070130815

44. Barham PJ, Keller A, Otun EL, Holmes PA (1984) Crystallization and morphology of a bacterial thermoplastic: poly-3-hydroxybutyrate. J Mater Sci 19:2781-2794. https://doi.org/10.1007/BF010 26954
45. Jandura P, Kokta B V., Riedl B (2000) Fibrous long-chain organic acid cellulose esters and their characterization by diffuse reflectance FTIR spectroscopy, solid-state CP/MAS 13C-NMR, and X-ray diffraction. J Appl Polym Sci 78:1354-1365

46. Gardea-Hernández G, Ibarra-Gómez R, Flores-Gallardo SG et al (2008) Fast wood fiber esterification. I. Reaction with oxalic acid and cetyl alcohol. Carbohydr Polym 71:1-8. https://doi. org/10.1016/j.carbpol.2007.05.014

47. Wei L, McDonald AG, Freitag C, Morrell JJ (2013) Effects of wood fiber esterification on properties, weatherability and biodurability of wood plastic composites. Polym Degrad Stab 98:1348-1361. https://doi.org/10.1016/j.polymdegradstab .2013 .03 .027

48. Newman RH (2004) Homogeneity in cellulose crystallinity between samples of Pinus radiata wood. Holzforschung 58:91-96. https://doi.org/10.1515/HF.2004.012

49. Heux L, Dinand E, Vignon MR (1999) Structural aspects in ultrathin cellulose microfibrils followed by 13C CP-MAS NMR. Carbohydr Polym 40:115-124. https://doi.org/10.1016/S0144 -8617(99)00051-X

50. Sun X-F, Sun RC, Sun J-X (2002) Acetylation of rice straw with or without catalysts and its characterization as a natural sorbent in oil spill cleanup. J Agric Food Chem 50:6428-6433. https://doi. org/10.1021/jf020392o

51. Marques G, Río JC, Gutiérrez A (2010) Lipophilic extractives from several nonwoody lignocellulosic crops (flax, hemp, sisal, abaca) and their fate during alkaline pulping and TCF/ ECF bleaching. Bioresour Technol 101:260-267. https://doi. org/10.1016/j.biortech.2009.08.036

52. Faruk O, Bledzki AK, Fink HP, Sain M (2012) Biocomposites reinforced with natural fibers: 2000-2010. Prog Polym Sci 37:1552-1596. https://doi.org/10.1016/j.progpolyms ci.2012.04.003

53. Meijer M, De, Haemers S, Cobben W, Militz H (2000) Surface energy determinations of wood: comparison of methods and wood species. Langmuir 44:9352-9359. https://doi.org/10.1021/la001 080n

54. Van Hazendonk JM, Van der Putten JC, Keurentjes JTF, Prins A (1993) A simple experimental method for the measurement of the surface tension of cellulosic fibres and its relation with chemical composition. Colloids Surf A\&nbsp; 81:251-261. https://doi. org/10.1016/0927-7757(93)80252-A

55. Berthet MA, Commandré JM, Rouau X et al (2016) Torrefaction treatment of lignocellulosic fibres for improving fibre/matrix adhesion in a biocomposite. Mater Des 92:223-232. https://doi. org/10.1016/j.matdes.2015.12.034

56. Yu H, Qin Z, Wang L, Zhou Z (2012) Crystallization behavior and hydrophobic properties of biodegradable ethyl cellulose-gpoly (3-hydroxybutyrate-co-3-hydroxyvalerate): the influence of the side-chain length and grafting density. Carbohydr Polym 87:2447-2454. https://doi.org/10.1016/j.carbpol.2011.11.022

57. Luo S, Cao J, McDonald AG (2016) Interfacial improvements in a green biopolymer alloy of poly(3-hydroxybutyrate-co-3-hydroxyvalerate) and lignin via in situ reactive extrusion. ACS Sustain Chem Eng 4:3465-3476. https://doi.org/10.1021/acssuschem eng.6b00495

58. Brunauer S, Deming LS, Deming WE, Teller E (1940) On a theory of the van der Waals adsorption of gases. J Am Chem Soc 62:1723-1732. https://doi.org/10.1021/ja01864a025

59. Banik G, Brückle I (2010) Principles of water absorption and desorption in cellulosic materials. Restaur Int J Preserv Libr Arch Mater 31:164-177. https://doi.org/10.1515/rest.2010.012

60. Hornsby PR, Hinrichsen E, Tarverdi K (1997) Preparation and properties of polypropylene composites reinforced with wheat and flax straw fibres. Part I Fibre characterization. J Mater Sci 32:443-449 
61. Panthapulakkal S, Sain M (2007) Agro-residue reinforced highdensity polyethylene composites: fiber characterization and analysis of composite properties. Composites Part A 38:1445-1454. https://doi.org/10.1016/j.compositesa.2007.01.015

62. Pukánszky B (1990) Influence of interface interaction on the ultimate tensile properties of polymer composites. Composites 21:255-262. https://doi.org/10.1016/0010-4361(90)90240-W

63. Dányádi L, Janecska T, Szabó Z et al (2007) Wood flour filled PP composites: compatibilization and adhesion. Composites Sci
Technol 67:2838-2846. https://doi.org/10.1016/j.compscitec h.2007.01.024

Publisher's Note Springer Nature remains neutral with regard to jurisdictional claims in published maps and institutional affiliations. 